\title{
Co-Culture of Microalgae, Cyanobacteria, and Macromycetes for Exopolysaccharides Production: Process Preliminary Optimization and Partial Characterization
}

\author{
S. Angelis • A. C. Novak • E. B. Sydney • V. T. Soccol • \\ J. C. Carvalho • A. Pandey $\bullet$ M. D. Noseda • \\ J. L. Tholozan • J. Lorquin • C. R. Soccol
}

Received: 9 November 2011 / Accepted: 24 February 2012 /

Published online: 14 March 2012

(C) Springer Science+Business Media, LLC 2012

\begin{abstract}
In this study, the biomass and exopolysaccharides (EPS) production in co-cultures of microalgae/cyanobacteria and macromycetes was evaluated as a technology for producing new polysaccharides for medical and/or industrial application. Based on biomass and EPS productivity of monocultures, two algae and two fungi were selected and cultured in different co-culture arrangements. The hydrosoluble EPS fractions from mono- and cocultures were characterized by ${ }^{13} \mathrm{C}$ NMR spectroscopy and gas chromatography coupled to mass spectrometry and compared. It was found that co-cultures resulted in the production of an EPS different from those produced by monocultures, showing fungal predominance with microalgal/cyanobacterial traces. Co-cultures conditions were screened (temperature, agitation speed, fungal and microalgae inoculation rate, initial $\mathrm{pH}$, illumination rate, and glucose concentration) in order to achieve maximum biomass and EPS production, resulting in an
\end{abstract}

S. Angelis

EMBRAPA, Colombo, Brazil

S. Angelis · A. C. Novak • E. B. Sydney • V. T. Soccol • J. C. Carvalho • C. R. Soccol $(\bowtie)$

Bioprocess Engineering and Biotechnology Department, Federal University of Paraná, CEP 81531-980

Curitiba, Paraná, Brazil

e-mail: soccol@ufpr.br

V. T. Soccol

Industrial Biotechnology, Universidade Positivo, CEP 81280-330 Curitiba, Paraná, Brazil

A. Pandey

Biotechnology Division, National Institute for Interdisciplinary Science and Technology, CSIR,

Trivandrum 695 019, India

M. D. Noseda

Biochemical and Molecular Biology Department, Federal University of Paraná, CEP 81531-980 Curitiba, Paraná, Brazil

J. L. Tholozan · J. Lorquin

IRD, Marseille, France 
increase of 33 and $61 \%$ in exopolysaccharides and biomass productions, respectively (patent pending).

Keywords Co-culture $\cdot$ Microalgae $\cdot$ Macromycetes $\cdot$ Exopolysaccharides

\section{Introduction}

Fungi and algae are microorganisms that may have innumerous industrial application. They are mostly used in food or fed in form of protein supplement or lipids source and also for the extraction of flavors and other metabolites, such as enzymes and polysaccharides. Fungal polysaccharides are already used in food industry, for example, while those from microalgae and cyanobacteria are not yet completely explored. The biopolymers produced may also have potential industrial applications, as well in human health, as several fungal polysaccharides are intensively researched as antitumor agents.

Some exopolysaccharides (EPS) from microalgae and mushrooms are able to stimulate the nonspecific immune system and to exert antitumor activity through the stimulation of the host's defense mechanism [1-5]. Molecular weight, degree of branching, numbers of substituent, as well its ultrastructure, including the presence of single and triple helices, significantly affect the EPS biological activity [6]. The high water solubility, with low level of branching and high molecular weight seems to be correlated to higher antitumor activity [7] and varies according to culture conditions.

Macromycetes have been studied extensively for their degradation capacity, specially the so-called white rot fungi, which have the capacity to degrade lignin [8] and xenobiotics [9]. There are many evidences that the extracellular polysaccharides (EPS) produced by these lignocellulolitic fungi play an important role in wood decay $[8,10]$. According to [11], the gel formed by these biopolymers prevents the hyphal dehydration, allows cell adherence to others cells or surfaces, and can also immobilize exocellular enzymes.

The ability of microalgae to produce extracellular polysaccharides has been studied since the beginning of the 1950s. In stress conditions, these microorganisms produce a large amount of EPS, which is possibly a metabolic strategy for their growth and development in unfavorable conditions [12].

Co-culture systems are composed of at least two kinds of microorganisms. This interaction results in stress conditions, to which the microorganisms may respond producing large amounts of EPS, for example, as a metabolic strategy to grow in these unfavorable conditions.

The aim of this work was to evaluate the competition or synergy effect of co-cultured macromycetes and algae as a stress condition for favoring EPS production. Considering the innumerous applications of fungal, microalgal, and cyanobacterial EPS, the stressful effects of co-cultures in EPS composition were also evaluated.

\section{Materials and Methods}

Screening

Microorganisms Eight strains of Basidiomycetes and four strains of microalgae were screened. The pure cultures came from the Bioprocess Engineering and Biotechnology Department, Federal University of Paraná, Brazil. 
Fungi Cultivation The medium was composed by (in grams per liter): glucose, 20; yeast extract, $3 ; \mathrm{K}_{2} \mathrm{HPO}_{4}, 0.6$, and $\mathrm{MgSO}_{4}, 0.3 ; \mathrm{pH}$ 6.0. Erlenmeyer flasks containing $250 \mathrm{~mL}$ of sterilized culture medium were inoculated with a suspension in sterile water of fungal mycelium grown on potato dextrose agar slants (the so-called pre-inoculum). Incubation was done at $29{ }^{\circ} \mathrm{C}$ on a shaker at $250 \mathrm{rpm}$. A scale-up was performed, transferring the preinoculum to $600 \mathrm{~mL}$ of medium culture, prepared with same components, and incubated at the same conditions. Dry weight of mycelium was measured after repeated washing of the mycelial pellet with distilled water and drying overnight at $70{ }^{\circ} \mathrm{C}$ until constant weight.

Microalgae Cultivation The Spirulina platensis LPBPA culture was performed in Zarrouk medium [13] and the Chlorella vulgaris LPB06 in modified Bristol's medium [14]. Incubation was done in $250-\mathrm{mL}$ Erlenmeyer flasks at $29^{\circ} \mathrm{C}$ under illumination of white fluorescent light ( $24 \mathrm{~h}$ light, 3,000 lx). A scale-up was made by transferring the pre-inoculum to 3,000 $\mathrm{mL}$ of medium culture, prepared with the same components, and incubated at the same conditions.

Screening Eight strains of Basidiomycetes and four strains of microalgae were separately tested for EPS and biomass production. The species are listed in Table 1. For the screening, the incubation period was 10 days for Basidiomycetes and 20 days for microalgae. The final broth was filtrated to separate the biomass, which was washed twice with distilled water and quantified by dry weight $\left(105{ }^{\circ} \mathrm{C}\right.$ to constant weight). Ethanol was added to the culture filtrate $(4: 1 \mathrm{v} / \mathrm{v})$ and after $24 \mathrm{~h}$ at $4{ }^{\circ} \mathrm{C}$ the precipitated biopolymer was separated by centrifugation (10,000 rpm for $10 \mathrm{~min})$ and also quantified by drying and weighting.

\section{Co-culture}

Following the screening, microorganisms that showed higher biomass and exopolysaccharides production were arranged according to the Table 2. Each combination received a correspondent code, as informed in Table 2. Co-cultures were performed using a 1:1 mixture of fungi and algae medium. The co-culture was followed daily by microscopy, certifying that both microorganisms were growing. Thus, co-cultures biomass quantifications intended to

Table 1 Basidiomycetes, microalgae, and cyanobacteria strains evaluated in this study

\begin{tabular}{lll}
\hline & Code & Species \\
\hline Basidiomycetes & LPB26 & Ganoderma applanatum \\
& LPB 57 & Lentinus edodes \\
& LPB99 & Lentinus edodes \\
& LPB18 & Lentinus edodes \\
LPB24 & Trametes versicolor \\
LPB09 & Pleurotus ostreatus \\
LPB03 & Agaricus blazei \\
LPanobacteria & LPB06 & Ganoderma lucidum \\
& LPB08 & Chlorella vulgaris \\
& LPB PA & Chlorella minutisima \\
& LPB 25 & Spirulina platensis \\
\hline
\end{tabular}


Table 2 Selected microorganisms arrangement for co-culture essays

\begin{tabular}{ll}
\hline Microorganisms in co-culture & Code \\
\hline A. blazei + T. versicolor & $\mathrm{A}+\mathrm{T}$ \\
C. vulgaris + S. platensis & $\mathrm{C}+\mathrm{S}$ \\
A. blaze + C. vulgaris & $\mathrm{A}+\mathrm{C}$ \\
A. blaze + S. platensis & $\mathrm{A}+\mathrm{S}$ \\
T. versicolor + C. vulgaris & $\mathrm{T}+\mathrm{C}$ \\
T. versicolor + S. platensis & $\mathrm{T}+\mathrm{S}$
\end{tabular}

quantify algal and fungal biomass together. Biomass and EPS productions in co-cultures are an average of five trials.

\section{EPS Characterization}

EPS Extraction The broth was vacuum filtered (paper filter Whatman no. 1), and the filtrate was concentrated to one fourth of the original volume through rotary evaporation at $50{ }^{\circ} \mathrm{C}$. The filtrated was then dialyzed in a membrane $(12-14 \mathrm{kDa})$, mixed with four times its volume of absolute ethanol, stirred vigorously, and left overnight at $4{ }^{\circ} \mathrm{C}$ and centrifuged at $10,000 \mathrm{rpm}$ for $10 \mathrm{~min}$. The supernatant was discarded and the purified EPS lyophilized. EPS characterization results are an average of five trials.

Sugar Content The carbohydrate quantification was done using phenol-sulfuric method [15], and the quantification of residual sugar (glucose) was carried out according to Somogy and Nelson [16]. The absorbance reading for both methodologies was performed in spectrophotometer (Power Wave XS, BioTek, USA).

Protein Content The quantification of protein was performed according to Lowry [17]. The determination of absorbance was also carried out in a spectrophotometer (Power Wave XS, BioTek, USA).

Table 3 Randomized Plackett-Burman experimental design for evaluating factors influencing biomass and EPS production by co-cultures

\begin{tabular}{llllllll}
\hline Run & \multicolumn{2}{l}{ Variables/levels } \\
\cline { 2 - 8 } & $\begin{array}{l}\text { Culture } \\
\text { temperature } \\
\left({ }^{\circ} \mathrm{C}\right)\end{array}$ & $\begin{array}{l}\text { Agitation } \\
\text { speed }(\mathrm{rpm})\end{array}$ & $\begin{array}{l}\text { Fungal } \\
\text { inoculation rate } \\
(v / v)(\%)\end{array}$ & $\begin{array}{l}\text { Microalgae } \\
\text { inoculation rate } \\
(v / v)(\%)\end{array}$ & Initial pH & $\begin{array}{l}\text { Illumination } \\
\text { rate }(\mathrm{lx})\end{array}$ & $\begin{array}{l}\text { Glucose } \\
\text { concentration } \\
(\mathrm{g} / \mathrm{L})\end{array}$ \\
\hline 1 & 25 & 120 & 15 & 50 & 4.5 & 50 & 50 \\
2 & 30 & 120 & 5 & 10 & 7.0 & 50 & 50 \\
3 & 25 & 180 & 15 & 50 & 7.0 & 50 & 10 \\
4 & 30 & 180 & 5 & 10 & 4.5 & 50 & 10 \\
5 & 25 & 120 & 15 & 50 & 7.0 & 1,000 & 10 \\
6 & 30 & 120 & 5 & 10 & 4.5 & 1,000 & 10 \\
7 & 25 & 180 & 15 & 50 & 4.5 & 1,000 & 50 \\
8 & 30 & 180 & 5 & 10 & 7.0 & 1,000 & 50 \\
\hline
\end{tabular}


Table 4 Box-Behnken design matrix in the evaluation of factors influencing biomass and polysaccharide production in the best co-culture system

\begin{tabular}{|c|c|c|c|c|c|c|}
\hline \multirow[t]{3}{*}{ Runs } & \multicolumn{6}{|c|}{ Variables/levels } \\
\hline & \multicolumn{2}{|c|}{ Glucose concentration } & \multicolumn{2}{|c|}{ Agitation speed } & \multicolumn{2}{|c|}{ Initial $\mathrm{pH}$} \\
\hline & $\operatorname{Var}_{1}(\mathrm{~g} / \mathrm{L})$ & Code $\operatorname{Var}_{1}$ & $\operatorname{Var}_{2}(\mathrm{rpm})$ & Code $\operatorname{Var}_{2}$ & $\mathrm{Var}_{3}$ & Code $\operatorname{Var}_{3}$ \\
\hline 1 & 45 & 0 & 140 & -1 & 4.5 & -1 \\
\hline 2 & 55 & 0 & 140 & 0 & 4.5 & 0 \\
\hline 3 & 45 & 1 & 220 & 1 & 4.5 & 0 \\
\hline 4 & 55 & 1 & 220 & -1 & 4.5 & 0 \\
\hline 5 & 45 & 1 & 180 & 0 & 3.5 & -1 \\
\hline 6 & 55 & -1 & 180 & 1 & 3.5 & 0 \\
\hline 7 & 45 & 0 & 180 & -1 & 5.5 & 1 \\
\hline 8 & 55 & 0 & 180 & 1 & 5.5 & -1 \\
\hline 9 & 50 & 0 & 140 & 0 & 3.5 & 0 \\
\hline 10 & 50 & -1 & 220 & 0 & 3.5 & 1 \\
\hline 11 & 50 & -1 & 140 & -1 & 5.5 & 0 \\
\hline 12 & 50 & 0 & 220 & 0 & 5.5 & 0 \\
\hline 13 & 50 & 0 & 180 & 1 & 4.5 & 1 \\
\hline 14 & 50 & -1 & 180 & 0 & 4.5 & -1 \\
\hline 15 & 50 & 1 & 180 & 0 & 4.5 & 1 \\
\hline
\end{tabular}

Pareto Chart of Standardized Effects; Variable: VAR8

7 Factor Screening Design; MS Residual $=.0003013$

DV: VAR8

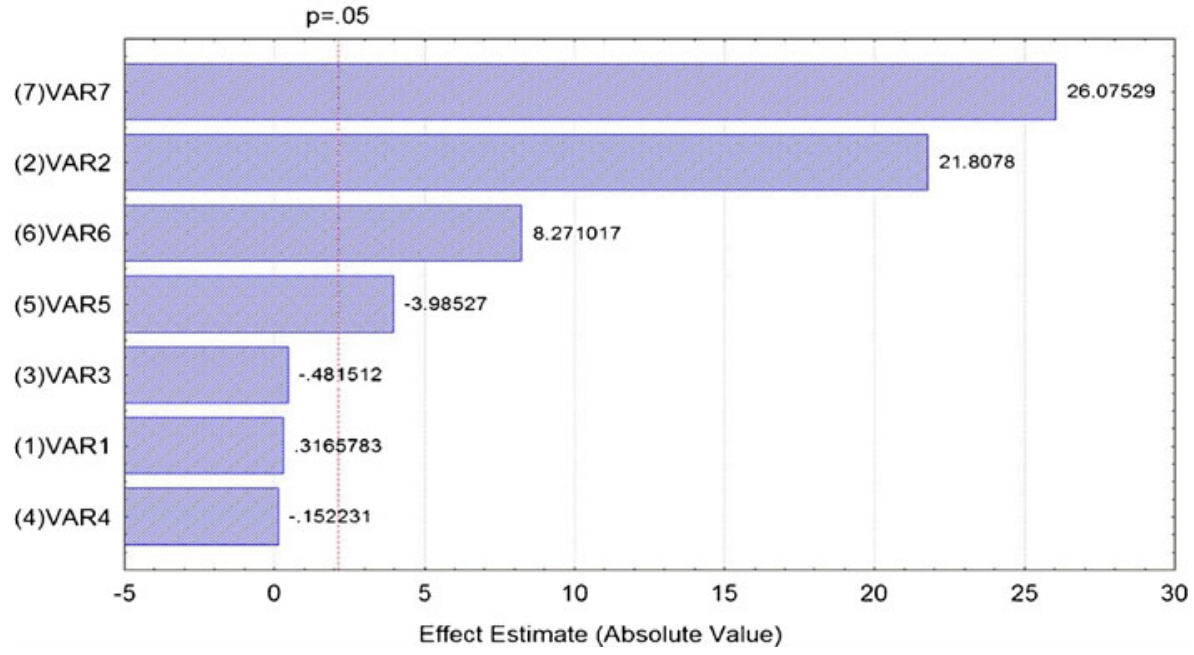

Fig. 1 Pareto chart rationalizing the effect of each variable on the production of biomass (left) and extracellular polysaccharide (right) by A. blazei and C. vulgaris co-culture. The vertical line indicates confidence level of $95 \%$ for the effects. VAR1-VAR7 indicates culture temperature, agitation speed, microalgal inoculation density, fungal inoculation density, initial $\mathrm{pH}$, illumination, rate, and glucose concentration, respectively 

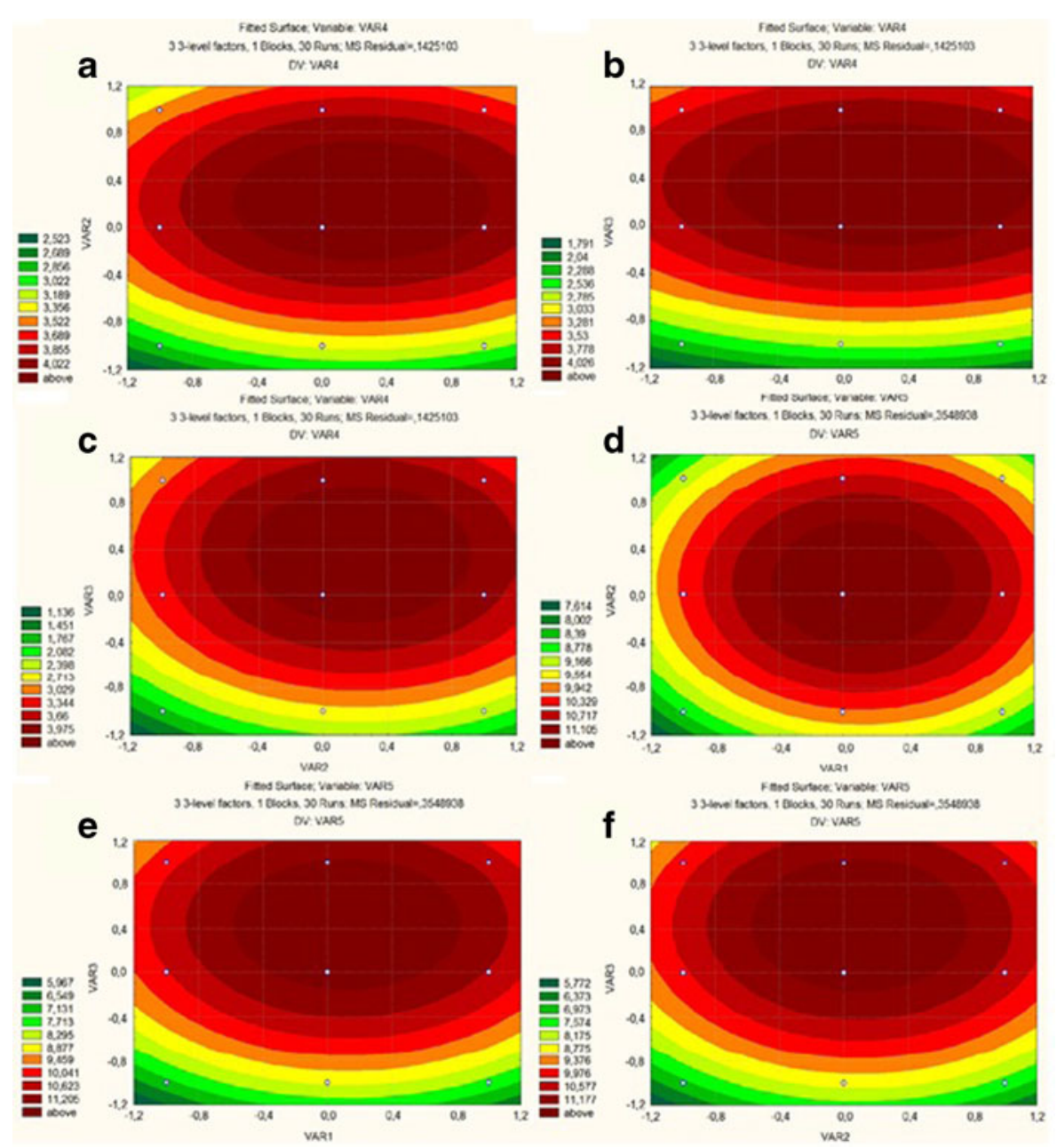

Fig. 2 Contour surface plots of the EPS $(\mathbf{a}-\mathbf{c})$ and biomass $(\mathbf{d}-\mathbf{f})$ yield. In each plot, the influence of two variables is shown while the third is set at the central level. a Glucose concentration (VARI) vs. agitation speed $(V A R 2)$ and their interactive effect with initial $\mathrm{pH}(V A R 3)$ set at center level; b glucose concentration (VAR1) vs. initial $\mathrm{pH}(V A R 3)$ and their interactive effect with agitation speed (VAR2) set at center level; $\mathbf{c}$ effects of agitation speed (VAR2) vs. initial $\mathrm{pH}(V A R 3)$ and their interactive effect with glucose concentration $(V A R 1)$ set at center level; $\mathbf{d}$ effects of glucose concentration $(V A R 1)$ vs. agitation speed (VAR2) and their interactive effect with initial $\mathrm{pH}(V A R 3)$ set at center level; e glucose concentration (VARl) vs. initial $\mathrm{pH}(V A R 3)$ and their interactive effect with agitation speed (VAR2) set at center level; and $\mathbf{f}$ agitation speed (VAR2) vs. initial $\mathrm{pH}$ $(V A R 3)$ and their interactive effect with glucose concentration $(V A R I)$ set at center level

Monosaccharide Composition Monosaccharide composition analysis was performed according to [18]. Approximately $1 \mathrm{mg}$ of EPS was treated with $0.5 \mathrm{~mL}$ of $2 \mathrm{M}$ trifluoracetic acid during $1 \mathrm{~h}$ at $121{ }^{\circ} \mathrm{C}$. The acid was eliminated by evaporation, followed by $\mathrm{NaBH}_{4}$ reduction, acetylation, and analysis by gas chromatography (GC) and GC coupled to mass spectrometry (GC-MS). The alditol acetates produced from the EPS samples were analyzed by GC-MS using a Varian 3.300 gas chromatograph equipped with DB-225 (30 m× $0.25 \mathrm{~mm}$ ) fused silica capillary columns interfaced to a Finnigan Mat ITD 800 mass 
Table 5 Evaluation of biomass and EPS production and productivities for the strains tested

\begin{tabular}{|c|c|c|c|c|c|c|}
\hline & Code & Specie & $\begin{array}{l}P_{\mathrm{x}} \\
(\mathrm{g} \text { dry wt/L) }\end{array}$ & $Y_{\mathrm{X} / \mathrm{S}}$ & $\begin{array}{l}P_{\mathrm{P}} \\
(\mathrm{g} \text { dry wt/L) }\end{array}$ & $Y_{\mathrm{P} / \mathrm{S}}$ \\
\hline \multirow[t]{8}{*}{ Basidiomycetes } & $\mathrm{CC} 126$ & Ganoderma applanatum & 2.91 & 0.24 & 0.21 & 0.02 \\
\hline & CC57 & Lentinus edodes & 0.99 & 0.12 & 0.64 & 0.08 \\
\hline & CC299 & Lentinus edodes & 0.43 & 0.09 & 0.82 & 0.17 \\
\hline & $\mathrm{CC} 18$ & Lentinus edodes & 0.34 & 0.05 & 0.75 & 0.10 \\
\hline & $\mathrm{CC} 124$ & Trametes versicolor & 11.66 & 0.80 & 4.13 & 0.28 \\
\hline & LPB09 & Pleurotus ostreatus & 4.06 & 0.37 & 0.57 & 0.05 \\
\hline & LPB03 & Agaricus blazei & 9.22 & 0.51 & 3.44 & 0.19 \\
\hline & $\mathrm{CC} 144$ & Ganoderma lucidum & 0.92 & 0.14 & 1.39 & 0.20 \\
\hline \multirow[t]{4}{*}{ Microalgae/cyanobacteria } & LEB106 & Chlorella vulgaris & 2.71 & $-{ }^{\mathrm{a}}$ & 0.29 & $-{ }^{\mathrm{a}}$ \\
\hline & LEB108 & Chlorella minutisima & 1.36 & $-{ }^{\mathrm{a}}$ & 0,13 & $-{ }^{\mathrm{a}}$ \\
\hline & PARACAS & Spirulina platensis & 1.49 & $-{ }^{\mathrm{a}}$ & 0.49 & $-{ }^{\mathrm{a}}$ \\
\hline & LEB52 & Spirulina platensis & 1.35 & $-^{\mathrm{a}}$ & 0.31 & $-^{\mathrm{a}}$ \\
\hline
\end{tabular}

Data is an average of five trials

${ }^{a}$ Data not calculated once microalgae and cyanobacteria were cultivated autotrophically and $\mathrm{CO}_{2}$ mitigation was not evaluated

spectrometer. The injector and FID temperatures were $250{ }^{\circ} \mathrm{C}$. Helium was used as carrier

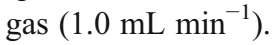

${ }^{13} \mathrm{C}$ NMR Spectroscopy The EPS structures were determined and compared using ${ }^{13} \mathrm{C}$ NMR spectroscopy. Resolution-enhanced 1D/2D 100.16 MHz NMR spectra were recorded in $\mathrm{D}_{2} 0$ on a Bruker spectrometer, 30,000 pulses with a pulse repetition time of $0.1 \mathrm{~s}$, at a probe temperature of 50 to $70{ }^{\circ} \mathrm{C}$ for polysaccharides. Prior to analysis, samples were dissolved to a polysaccharide concentration of $0.6 \%(w / v)$ in $\mathrm{D}_{2} \mathrm{O} / \mathrm{H}_{2} \mathrm{O}$. Chemical shifts are expressed in parts per million by reference to the $\alpha$-anomeric signal of external [1-13C] glucose (dC-1 92.9) for ${ }^{13} \mathrm{C}$. All NMR data were processed using TopSpin ${ }^{\circledR}$ software.

\section{Preliminary Optimization Steps}

In order to evaluate the most significant variables to the process of biomass and EPS production by co-culture, a randomized Plackett-Burman experimental design was used, evaluating seven variables, as shown in Table 3. The best co-culture was then analyzed through Box-Behnken design matrix (Table 4). This was carried out using the software Statistica 7.0 (StatSoft Inc., Tulsa, OK, USA). A Pareto chart displaying the magnitude of each factor estimate was generated by using the same software (Figs. 1 and 2).

\section{Results and Discussion}

\section{Screening}

Firstly, the fungi, microalgae, and cyanobacteria strains were screened in monocultures for biomass and EPS production capacity. The results are presented in Table 5. 

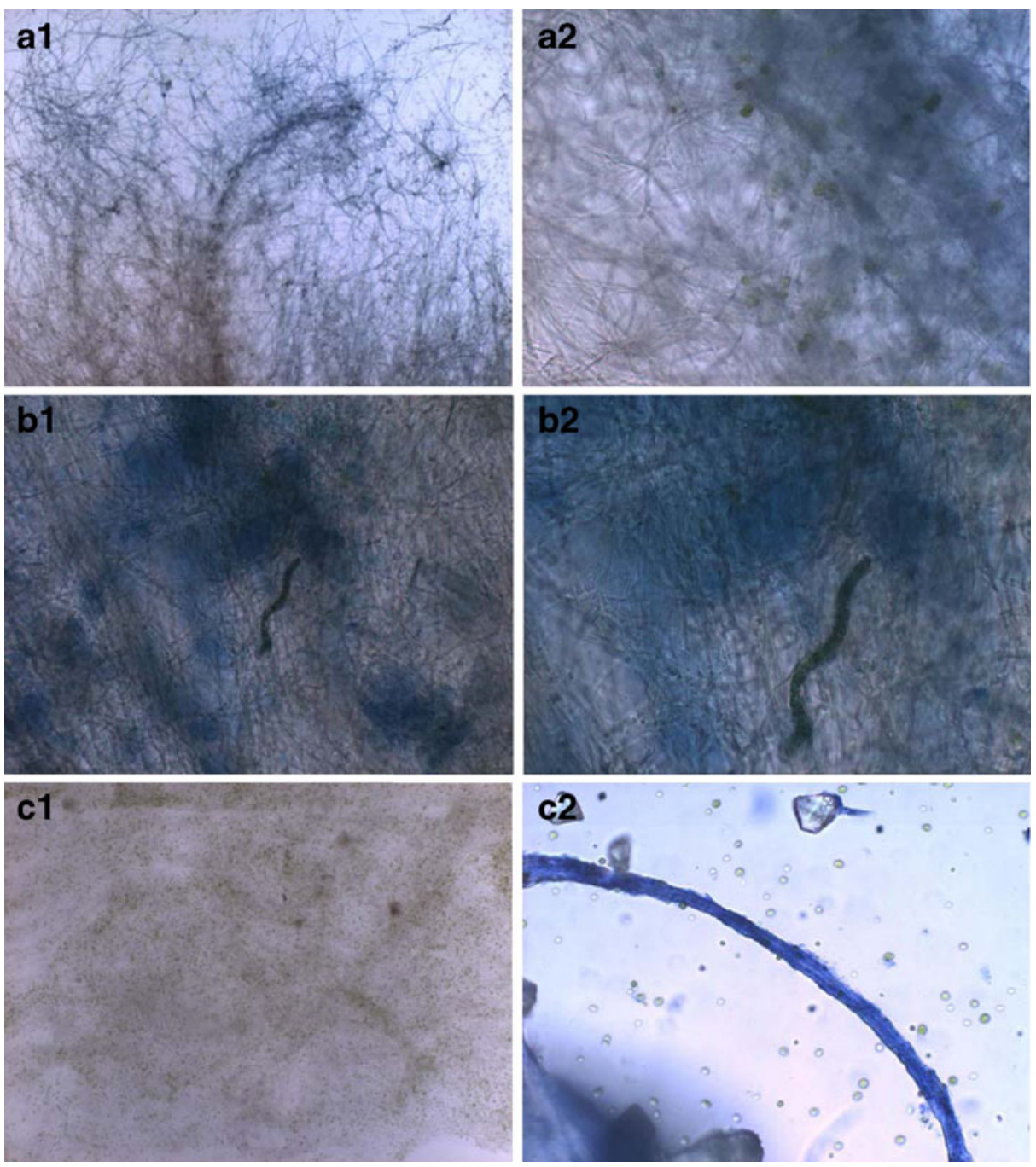

Fig. 3 Optical microscopical pictures of the co-cultures $(A 1, A 2) A$. blazei and C. vulgaris (amplification of $(A 1) \times 40$ and $(A 2) \times 200) ;(B 1, B 2) A$. blazei and S. platensis (amplification of $(B 1) \times 200$ and $(B 2) \times 400)$; and $(C 1, C 2)$ T. versicolor and $C$. vulgaris (amplification of $(C 1) \times 40$ and $(C 2) \times 200$ )

The yield $Y_{\mathrm{S} / \mathrm{P}}$ (conversion of glucose to polymer) varied from 0.017 to 0.283 , and the best yields were those of Trametes versicolor (0.283) and Ganoderma lucidum (0.207). The best EPS production was achieved by $T$. versicolor $\left(4.13 \mathrm{~g} / \mathrm{L}, Y_{\mathrm{S} / \mathrm{P}}=0.283\right)$ and Agaricus blazei $\left(3.44 \mathrm{~g} / \mathrm{L}, Y_{\mathrm{S} / \mathrm{P}}=0.192\right)$ in 10 days monocultures.

Some strains, such as Lentinus edodes and G. lucidum, showed a slow growth rate in the conditions tested, while others, such as $T$. versicolor, produced more than $10 \mathrm{~g} / \mathrm{L}$ of biomass. This great variability of EPS and biomass production and the absence of relation between them make the screening a key step. Considering the best biomass and EPS producers (Table 5), the following microorganisms were chosen for performing co-culture systems: $T$. versicolor, A. blazei, C. vulgaris, and S. platensis-PARACAS. 

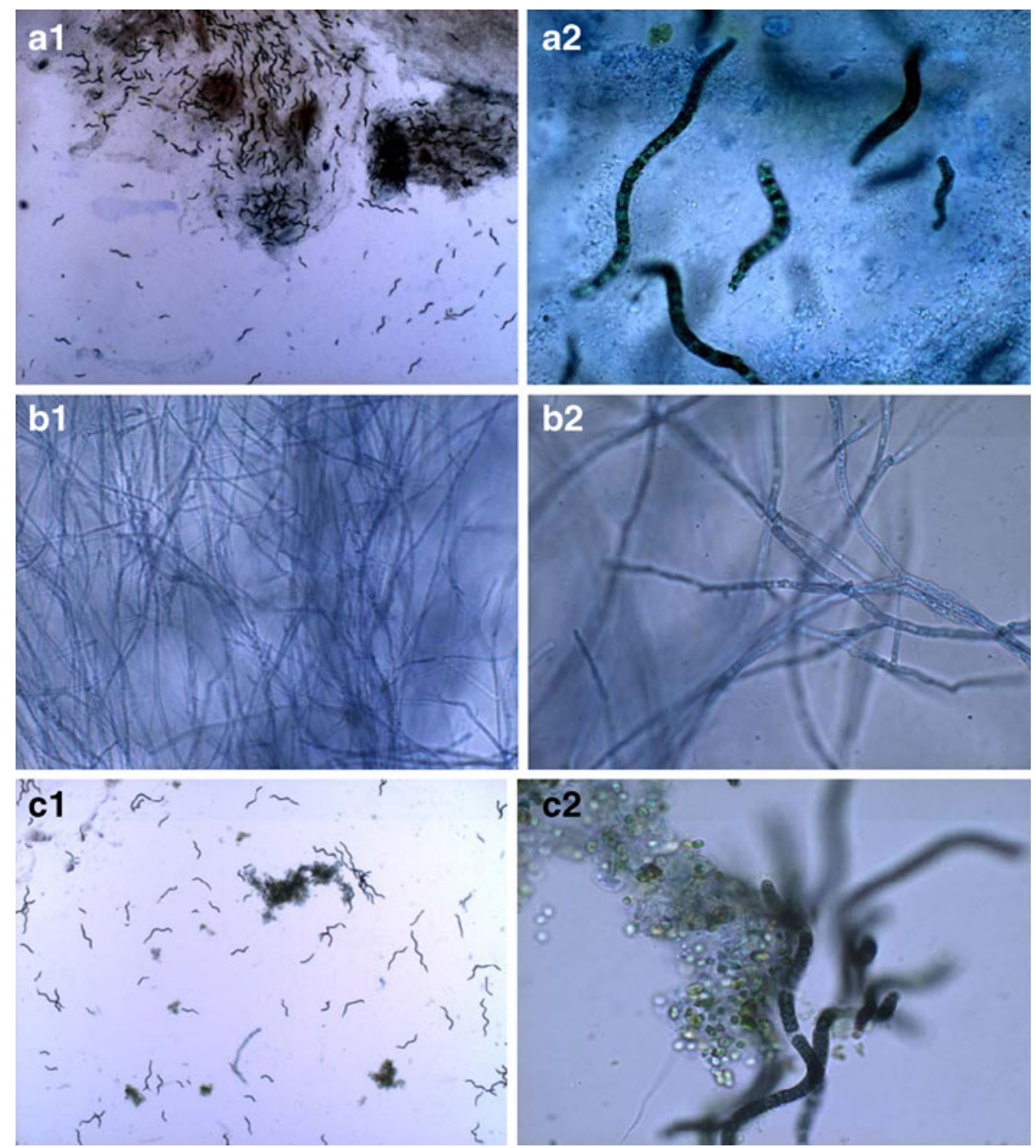

Fig. 4 Optical microscopical pictures of the co-cultures $(A 1, A 2)$ T. versicolor and $S$. platensis (amplification of $(A 1) \times 40$ and $(A 2) \times 200) ;(B 1, B 2)$ A. blazei and T. versicolor (amplification of $(B 1) \times 200$ and $(B 2) \times 400)$; and $(C 1, C 2) C$. vulgaris and $S$. platensis (amplification of $(C 1) \times 40$ and $(C 2) \times 400)$

\section{Co-Cultures}

Different arrangements between the four selected strains were carried in order to evaluate EPS characterization (Table 2). Figures 3 and 4 are microscopical pictures showing the presence of both microorganisms in the all the co-culture systems tested. Co-cultures were evaluated daily through optical microscopy to ensure that both microorganisms were growing, once through dry weight it was not possible to quantify separately the fungal and microalgal/cyanobacterial biomasses.

Table 6 compares the typical time courses for higher EPS production of mono- and co-cultures. Interestingly, in all cases, co-culture produced EPS much faster than monocultures. 
Table 6 Cultivation of $T$. versicolor, A. blazei, C. vulgaris, and S. platensis-PARACAS in pure cultures and in different co-culture arrangements. The typical time courses of EPS production are presented. Data is an average of five trials

\begin{tabular}{lcc}
\hline Culture & EPS (g/L) & Time (days) \\
\hline T. versicolor & 4.95 & 11 \\
A. blazei & 4.00 & 9 \\
A. blazei with T. versicolor & 5.26 & 5 \\
C. vulgaris & 0.95 & 24 \\
S. platensis & 1.04 & 26 \\
C. vulgaris with S. platensis & 1.48 & 22 \\
A. blazei with C. vulgaris & 5.17 & 5 \\
A. blazei with $S$. platensis & 5.04 & 4 \\
T. versicolor with C. vulgaris & 7.10 & 8 \\
T. versicolor with S. platensis & 5.42 & 4 \\
\hline
\end{tabular}

\section{EPS Characterization}

The crude EPS obtained from co-cultures and pure cultures of C. vulgaris, S. platensis, A. blazei, and T. versicolor were analyzed for protein, neutral sugar, and total sugar content. The results (Table 7) showed that their carbohydrate portions are composed of six to eight different types of monomer units, which is quite unusual in microbial polysaccharides of industrial interest. Significant differences in EPS monosaccharide composition from

Table 7 Protein content and carbohydrate content and monosaccharide composition of extracellular polysaccharides produced by the microorganisms separately and in co-culture

\begin{tabular}{|c|c|c|c|c|c|c|c|c|c|c|}
\hline & \multirow{2}{*}{$\begin{array}{l}\text { Protein } \\
\text { content } \\
(\% \text { EPS dw) }\end{array}$} & \multirow{2}{*}{$\begin{array}{l}\text { Carbohydrate } \\
\text { content } \\
\% \text { EPS dw) }\end{array}$} & \multicolumn{8}{|c|}{ Monosaccharide $(\mathrm{mol} \%)^{\mathrm{c}}$} \\
\hline & & & Rha & Fuc & Rib & Ara & Xyl & Man & Glu & Gal \\
\hline A. blazei $^{\mathrm{b}}$ & 13.2 & 55.3 & - & 0.4 & 2.1 & 0.2 & 6.5 & 87.3 & 3.1 & 0.4 \\
\hline T. versicolor ${ }^{\mathrm{b}}$ & 42.6 & 28.3 & 0.7 & 1.3 & 0.9 & 0.2 & 0.2 & 24.0 & 70.3 & 2.4 \\
\hline S. platensis ${ }^{\mathrm{a}}$ & 49.2 & 22.1 & 11.2 & 13.6 & 1.9 & 1.4 & 6.1 & 25.3 & 24.1 & 16.4 \\
\hline C. vulgaris ${ }^{\mathrm{a}}$ & 53.1 & 18.7 & 16.0 & 20.5 & 1.6 & 0.5 & 6.7 & 18.0 & 21.2 & 15.5 \\
\hline A. blazei $+T$. versicolor ${ }^{\mathrm{b}}$ & 51.3 & 25.3 & 2.0 & 4.3 & 2.2 & 0.4 & 0.6 & 67.2 & 5.8 & 17.5 \\
\hline A. blazei + S. platensis $^{\mathrm{b}}$ & 52.3 & 17.3 & 1.6 & 1.3 & 2.1 & 0.5 & 0.5 & 66.2 & 18.5 & 9.3 \\
\hline A. blazei+C. vulgaris $^{\mathrm{b}}$ & 15.3 & 37.2 & 3.1 & 3.3 & 2.8 & 2.7 & 4.0 & $\mathbf{5 7 . 2}$ & 6.1 & 20.8 \\
\hline T. versicolor $+S$. platensis ${ }^{\mathrm{b}}$ & 38.6 & 27.3 & 0.5 & 12.0 & 2.4 & 0.4 & 0.3 & 46.8 & 16.0 & 21.6 \\
\hline T. versicolor $+C$. vulgaris ${ }^{\mathrm{b}}$ & 30.0 & 45.0 & 1.2 & 7.9 & 2.1 & - & 0.6 & 60.8 & 15.8 & 11.6 \\
\hline S. platensis + C. vulgaris $^{\mathrm{b}}$ & 52.4 & 15.6 & 1.5 & - & - & 2.4 & 2.9 & 55.0 & 8.3 & 29.9 \\
\hline
\end{tabular}

Data is an average of five trials

$(-)$ not detected

${ }^{\text {a }}$ A 21-day-old culture was used for EPS biochemical analysis and to determine the monosaccharide composition

${ }^{\mathrm{b}}$ A 10-day-old culture was used for EPS biochemical analysis and to determine the monosaccharide composition

${ }^{\mathrm{c}}$ Compositional analyses determined after hydrolysis with M TFA for $4 \mathrm{~h}$ at $100{ }^{\circ} \mathrm{C}$

The numbers in bold shows the main constituents of the EPS analyzed 
a

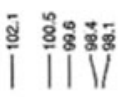

Suming
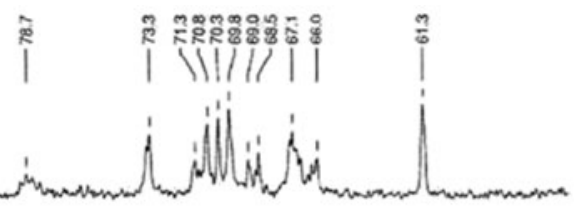

b $\quad$ :

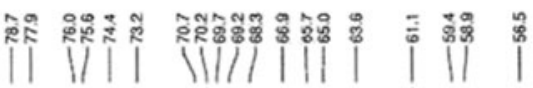

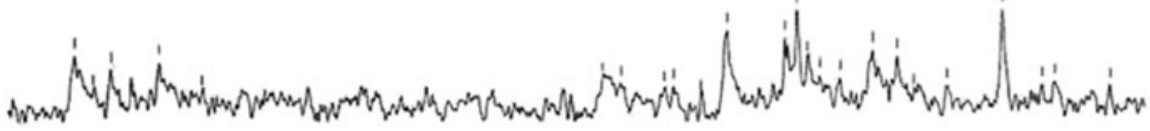

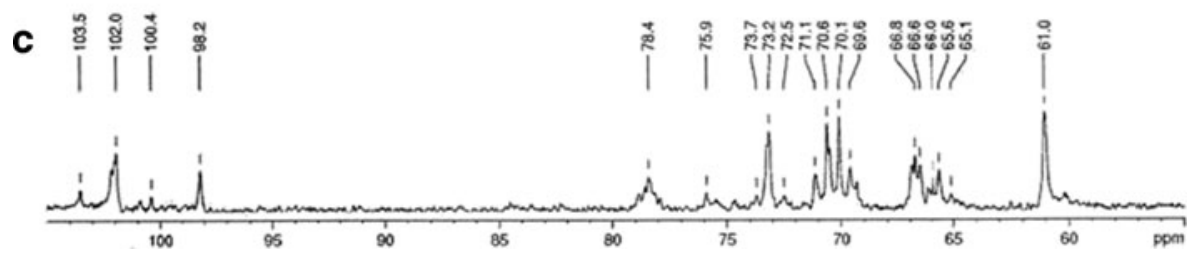

Fig. $5{ }^{13} \mathrm{C}$ NMR spectra of EPS produced by A. blazei with T. versicolor $(A)$, T. versicolor $(B)$, and A. blazei $(C)$. Acetone was used as internal standard, chemical shifts, in parts per million $(\delta)$

mono- and co-cultures can be observed in Table 7. Mannose was the predominant monosaccharide in all EPS, except in the one produced by $C$. vulgaris, where glucose and fucose dominated.

Besides monosaccharide composition, the EPS structures were analyzed by ${ }^{13} \mathrm{C}$ NMR. The NMR spectra (Figs. 5, 6, 7, 8, 9, and 10) of the co-cultured produced EPS showed a

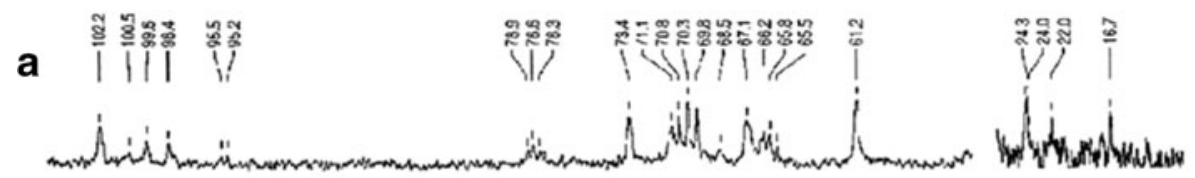

b 苗

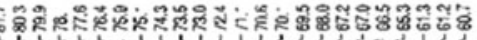
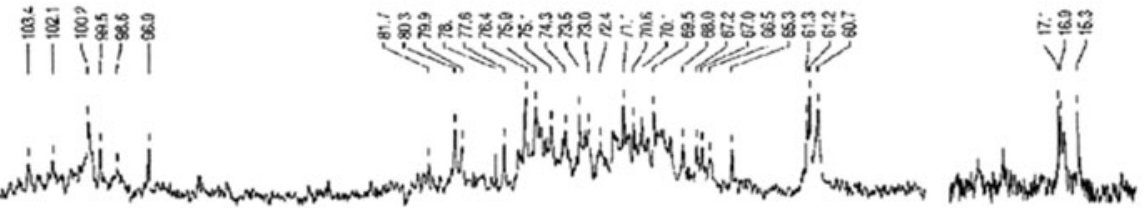

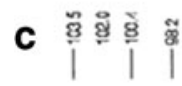

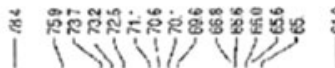
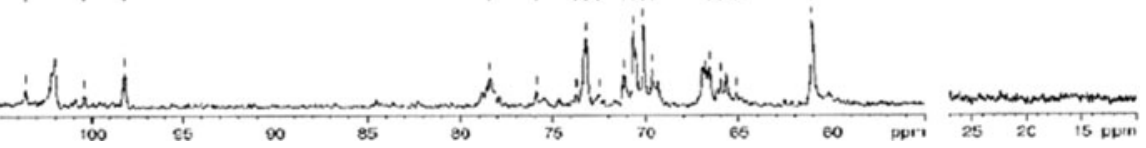

Fig. $6{ }^{13} \mathrm{C}$ NMR spectra of EPS produced by $A$. blazei with $S$. platensis $(A), S$. platensis $(B)$, and A. blazei $(C)$. Acetone was used as internal standard, chemical shifts in parts per million $(\delta)$ 


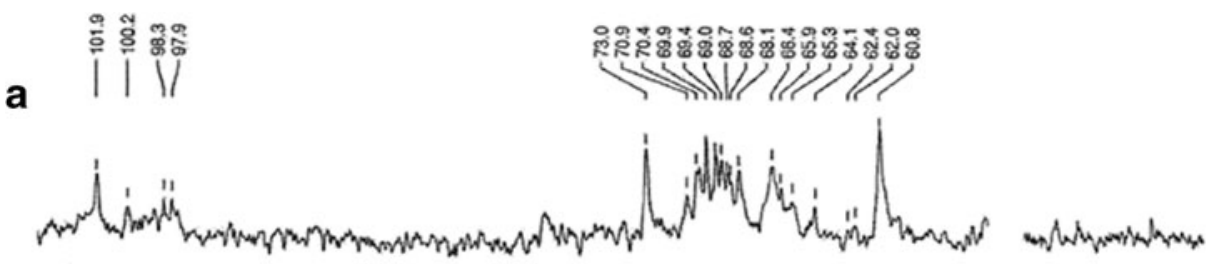

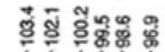 \\ b

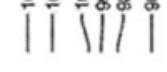

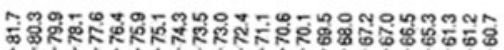

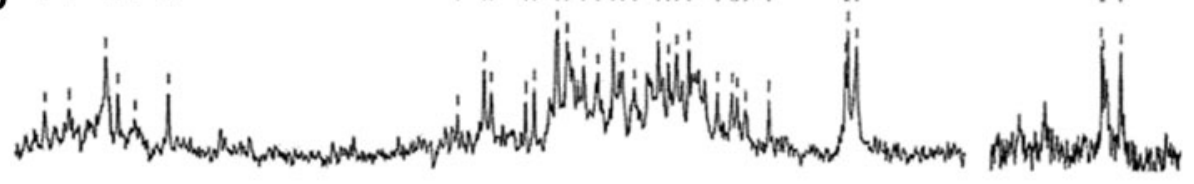

C
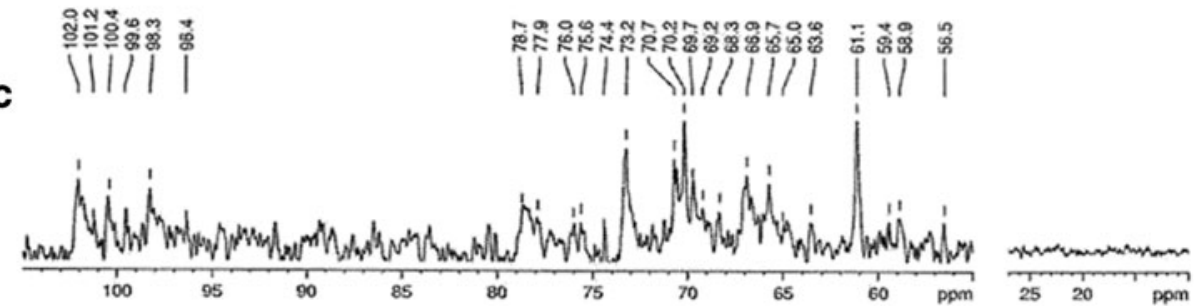

Fig. $7{ }^{13} \mathrm{C}$ NMR spectra of EPS produced by T. versicolor with S. platensis $(A), S$. platensis $(B)$, and $T$. versicolor $(C)$. Acetone was used as internal standard, chemical shifts, in parts per million $(\delta)$

fungal EPS predomination but with some differences in the structure, indicating that a third type of EPS is produced, different from the ones produced by monocultures. A standard EPS

${ }^{13} \mathrm{C}$ NMR analysis was carried out (Fig. 10) using tryptophan as a nitrogen source in the

\section{홓ํำ 쿵 \\ iोi}

a

b

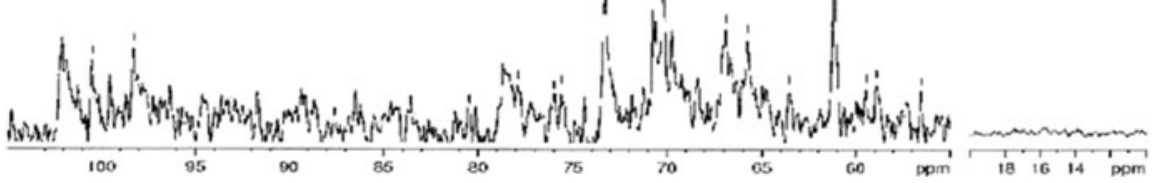

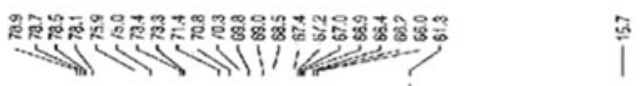

i

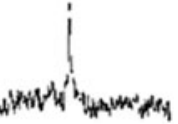

Fig. $8{ }^{13} \mathrm{C}$ NMR spectra of EPS produced by T. versicolor with $C$. vulgaris $(A)$ and $T$. versicolor $(B)$. Acetone was used as internal standard, chemical shifts, in parts per million $(\delta)$ 


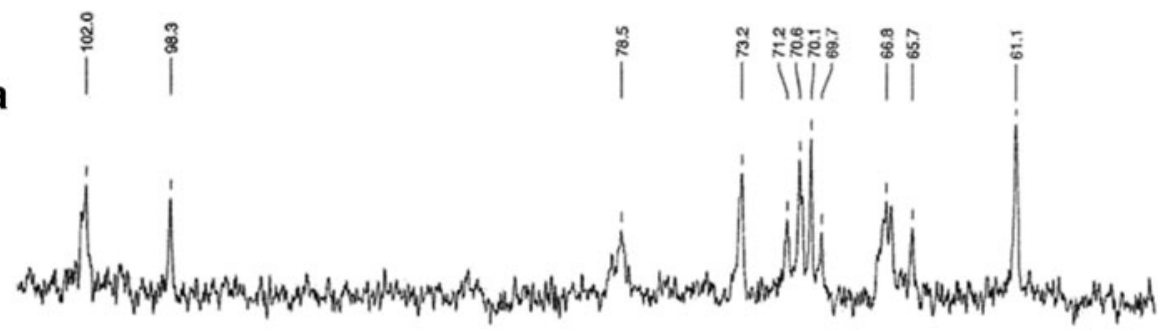

b
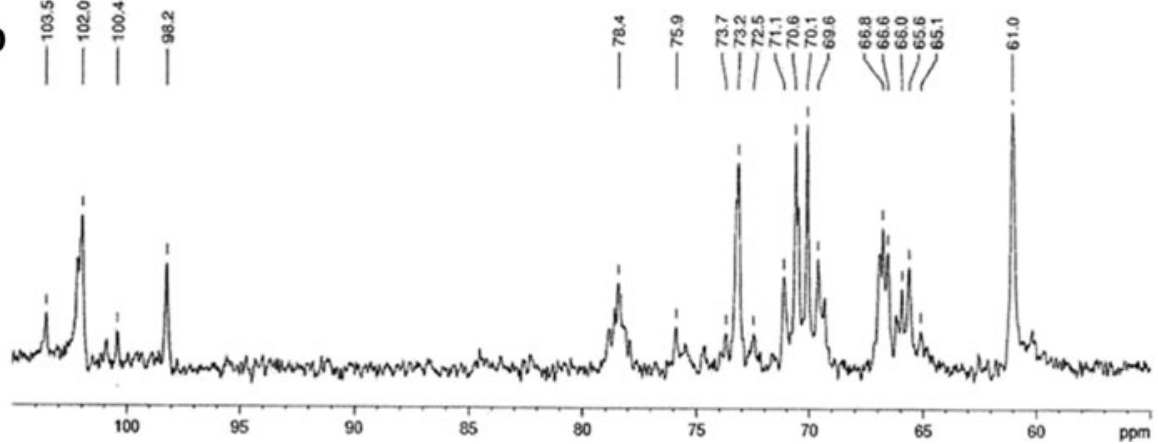

Fig. $9{ }^{13} \mathrm{C}$ NMR spectra of EPS produced by A. blazei with C. vulgaris $(A)$ and A. blazei (B). Acetone was used as internal standard, chemical shifts, in parts per million $(\delta)$
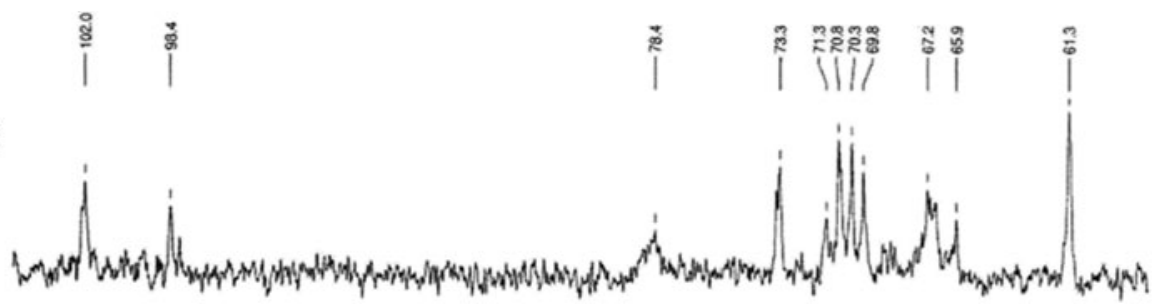

a

b
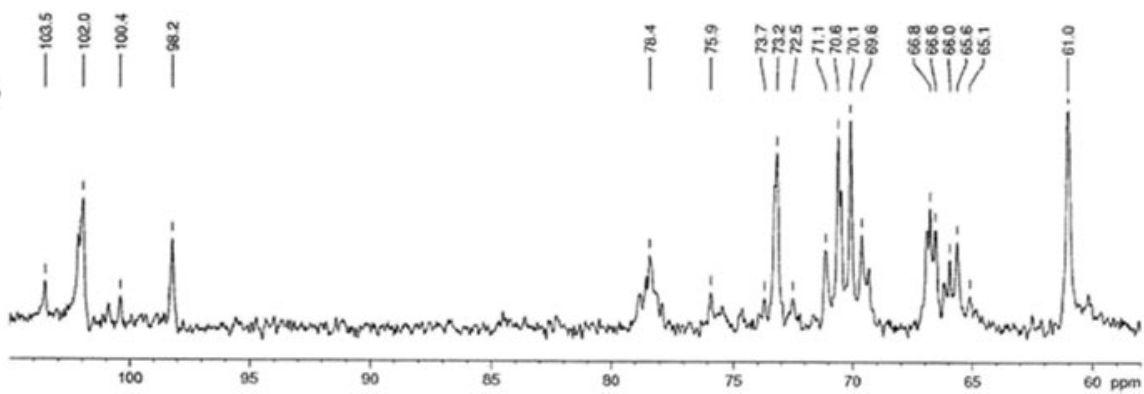

Fig. $10{ }^{13} \mathrm{C}$ NMR spectra for control. With different nitrogen sources: EPS produced by A. blazei using tryptophan in the medium composition $(A)$, EPS produced by $A$. blazei using yeast extract $(B)$. Acetone was used as internal standard, chemical shifts, in parts per million $(\delta)$ 
Table 8 Randomized Plackett-Burman experimental design for evaluating factors influencing biomass and polysaccharide production in co-cultures

\begin{tabular}{|c|c|c|c|c|c|c|c|c|}
\hline \multirow[t]{2}{*}{ Run } & \multicolumn{2}{|c|}{ A. blazei $+C$. vulgaris } & \multicolumn{2}{|c|}{ A. blazei + S. platensis } & \multicolumn{2}{|c|}{$\begin{array}{l}\text { T. versicolor }+C \text {. } \\
\text { vulgaris }\end{array}$} & \multicolumn{2}{|c|}{$\begin{array}{l}\text { T. versicolor }+S \text {. } \\
\text { platensis }\end{array}$} \\
\hline & $\begin{array}{l}\text { Biomass (g/ } \\
\text { L) }\end{array}$ & $\begin{array}{l}\text { EPS (g/ } \\
\mathrm{L})\end{array}$ & $\begin{array}{l}\text { Biomass (g/ } \\
\text { L) }\end{array}$ & $\begin{array}{l}\text { EPS (g/ } \\
\text { L) }\end{array}$ & $\begin{array}{l}\text { Biomass }(\mathrm{g} / \\
\mathrm{L})\end{array}$ & $\begin{array}{l}\text { EPS }(g / \\
\text { L) }\end{array}$ & $\begin{array}{l}\text { Biomass (g/ } \\
\mathrm{L})\end{array}$ & $\begin{array}{l}\text { EPS }(g / \\
L)\end{array}$ \\
\hline 1 & 6.14 & 2.48 & 6.19 & 2.05 & 4.49 & 3.28 & 6.74 & 2.62 \\
\hline 2 & 5.88 & 2.33 & 5.52 & 1.60 & 3.99 & 2.62 & 6.54 & 2.20 \\
\hline 3 & 4.12 & 1.42 & 2.53 & 0.92 & 2.77 & 1.95 & 3.83 & 1.67 \\
\hline 4 & 5.33 & 1.62 & 3.29 & 1.62 & 3.33 & 2.41 & 4.80 & 1.92 \\
\hline 5 & 6.68 & 2.08 & 4.20 & 1.66 & 3.61 & 2.98 & 4.68 & 2.02 \\
\hline 6 & 6.32 & 2.31 & 3.11 & 1.61 & 3.56 & 2.20 & 4.32 & 1.99 \\
\hline 7 & 9.43 & 4.00 & 9.28 & 3.73 & 5.19 & 4.25 & 7.64 & 3.84 \\
\hline 8 & 9.10 & 3.79 & 8.98 & 3.52 & 4.96 & 4.11 & 7.28 & 3.31 \\
\hline
\end{tabular}

Data is an average of five trials

cultivation media composition in order to show no influence of the EPS present in the yeast extract used in media composition of macromycetes during the experiments.

Figure 10 shows a highly complex spectrum (4B), with a variety of signals in the anomeric region, with five main signals at 100.2, 99.5, 96.9, 102.1, and $103.4 \mathrm{ppm}$. Signs in 17.1 and $15.3 \mathrm{ppm}$ corresponding to $\mathrm{CH}_{3}$ confirm the presence of 6-desoxy sugars (fucose and rhamnose) in agreement with the monosaccharide composition results. Signals around $16 \mathrm{ppm}$ and around 20 25 ppm possibly indicates presence of pyruvic acid acetal group.

\section{Co-Cultures Preliminary Optimization}

Seven variables (culture temperature, agitation speed, inoculation density, initial $\mathrm{pH}$, illumination intensity, and glucose concentration) were optimized for EPS and biomass production. The Plackett-Burman experimental design results for biomass and EPS production in co-cultures are shown in Table 8. A. blazei and C. vulgaris co-culture produced more biomass and EPS and was, thus, chosen for the next steps.

The Pareto chart for the co-culture of A. blazei and C. vulgaris is shown in Fig. 1. Culture temperature did not show a significant effect, while microalgal inoculation density exhibited negative influence, and agitation speed, fungal inoculation density, illumination rate, and glucose concentration showed positive effect.

Based on the Pareto chart, glucose concentration, agitation speed, and initial $\mathrm{pH}$ were selected as factors for further optimization. Light intensity was then fixed at 3,000 lx. Other variables with less significant effect were not included in the next step but were used in all trials at their low level (considering low cost of production).

Using the Box-Behnken method, a set of experiments with appropriate combinations of glucose concentration, agitation speed, and initial $\mathrm{pH}$ for the co-culture of $A$. blazei and $C$. vulgaris was conducted, as indicated in Table 4. Contour surface plots of EPS and biomass yields reflecting changes in independent variables culture temperature, agitation speed, and fungal inoculation density are presented in Fig. 2.

These surfaces show that the EPS and biomass yields increased with increasing glucose concentration until approximately $52 \mathrm{~g} / \mathrm{L}$ but decreased slowly beyond that range. The 
agitation speed (maximum productivity at approximately $200 \mathrm{rpm}$ ) and the $\mathrm{pH}$ (maximum productivity at approximately 5.0) showed a similar behavior. Cultures carried in the optimized fermentation conditions showed an average increase of $61 \%$ in biomass and $33 \%$ in EPS production.

\section{Conclusion}

The present work presents an innovative technological process of EPS production through cyanobacteria, microalgae, and Basidiomycetes co-culture in submerged fermentation (patent pending). When cultivated in co-culture, EPS production was favored and time of fermentation was significantly reduced. Significant enhancement of EPS and biomass production were achieved using Plackett-Burman followed by Box-Behnken design matrix. The composition and structure of the EPS produced indicated the production of a new EPS composed by a mixture of the EPS produced separately by each microorganism but mainly with fungal predominance. This indicates the existence of a synergistic effect, rather than an addition effect, in EPS production when co-cultures are performed. Further studies are therefore required to better characterize the EPS and evaluate medical and/or industrial applications.

\section{References}

1. Chihara, G., Hamuro, J., Maeda, Y. Y., Arai, Y., \& Fukuoka, F. (1970). Cancer Research, 30, $2776-2781$.

2. Fujimiya, Y., Suzuki, Y., Oshiman, K., Kobori, H., Moriguchi, K., Nakashima, H., et al. (1999). Biochemistry and Molecular Biology International, 47, 707-714.

3. Wasser, S., \& Weis, A. (1999). Critical Reviews in Immunology, 19, 65-96.

4. Lindequist, U., Niedermeyer, T., \& Jülich, W. (2005). eCAM, 2, 285-299.

5. Fan, L., Soccol, A. T., Pandey, A., \& Soccol, C. R. (2007). LWT-Food Science and Technology, 40, 30 36.

6. Suzuki, Y., Adachi, Y., Ohno, N., \& Yadomae, T. (2001). Biological and Pharmaceutical Bulletin, 24, 811-819.

7. Zjawiony, J. K. (2004). Journal of Natural Products, 67, 300-310.

8. Sánchez, C. (2009). Biotechnology Advances, 27, 185-194.

9. Rabinovich, M. L., Bolobova, A. V., \& Vasil'chenko. (2004). Applied Biochemistry and Microbiology, 40, 1-17.

10. Gutiérrez, A. (1995). PhD Thesis, Facultad de Farmacia, España: Universidad de Sevilla.

11. Catley, B. (1992). In D. K. Arora, R. P. Elander, K. G. Mukerji (Eds.), Handbook of applied mycology, vol 4: Fungal biotechnology (pp. 259-279). New York: Dekker.

12. Tribelli, P. M., \& López, N. I. (2011). Extremophiles, 15, 541-547.

13. Zarrouk, C. (1966). Ph.D Thesis, Université Des Paris, Paris, France

14. Watanabe, A. (1960). Journal of General and Applied Microbiology, 6, 1-4.

15. Dubois, M. (1956). Analytical Chemistry, 28, 350-356.

16. Somogyi-Nelson. (1952). Journal of Biological Chemistry, 195, 19.

17. Lowry, O. (1951). Journal of Biological Chemistry, 193, 265.

18. Yang, X. M., Beyenal, H., Harkin, G., \& Lewandowski, Z. (2000). Journal of Microbiological Methods, 39, 109-119. 